\title{
Compact filtering monopole patch antenna with dual-band rejection
}

\author{
Sun-Woong Kim and Dong-You Choi*
}

*Correspondence: dychoi@ chosun.ac.kr

Department of Information and Communication Engineering, Chosun University, Gwangju, Republic of Korea

\begin{abstract}
In this paper, a compact ultra-wideband patch antenna with dual-band rejection is proposed. The proposed antenna filters 3.3-3.8 GHz WiMAX and 5.15-5.85 GHz WLAN by respectively rejecting these bands through a $C$-shaped slit and $a \lambda_{\mathrm{g}} / 4$ resonator. The $\lambda_{\mathrm{g}} / 4$ resonator is positioned as a pair, centered around the microstrip line, and a C-type slit is inserted into an elliptical patch. The impedance bandwidth of the proposed antenna is 2.9-9.3 GHz, which satisfies the bandwidth for ultra-wideband communication systems. Further, the proposed antenna provides dual-band rejection at two bands: 3.2-3.85 and 4.7-6.03 GHz. The radiation pattern of the antenna is omnidirectional, and antenna gain is maintained constantly while showing -8.4 and $-1.5 \mathrm{dBi}$ at the two rejected bands, respectively.
\end{abstract}

Keywords: UWB, Dual-band rejection, Monopole patch antenna, WLAN, WiMAX

\section{Introduction}

The unlicensed use of ultra-wideband (UWB) set by the United States Federal Communications Commission requires the satisfaction of $-41.3 \mathrm{dBm} / \mathrm{MHz}$ noise strength a frequency band ranging between 3.1 and $10.6 \mathrm{GHz}$, along with $25 \%$ fractional bandwidth and at least $500 \mathrm{MHz}$ frequency bandwidth (Dullaert and Rogier 2010).

For UWB antennas, proposals have been developed to reduce interference from other UWB bands and for realizing a wide bandwidth with a stable radiation pattern (Kim and Min 2009; Kim and Kim 2010). To satisfy these requirements, a variety of structures for UWB antennas have been proposed, such as bow-tie antennas (Kiminami and Hirata 2004; Dadgarpour et al. 2009) that are easy to mount inside systems, elliptical antennas (Jang and Hwang 2008), Vivaldi antennas (Hood et al. 2008), and fractal antennas (Oraizi and Hedayati 2011).

Two bands coexist in the unlicensed use of UWB: IEEE 802.16 WiMAX (3.3-3.8 GHz) and IEEE 802.1a WLAN (5.15-5.85 GHz). However, these two bands are known to degrade the performance as a result of their interference with UWB communication systems.

Thus, this paper proposes the insertion of a $\lambda_{\mathrm{g}} / 4$ resonator and a C-shaped slit into an antenna in order to reject both WiMAX and WLAN bands. To reject WiMAX, a pair of

(c) 2016 The Author(s). This article is distributed under the terms of the Creative Commons Attribution 4.0 International License (http://creativecommons.org/licenses/by/4.0/), which permits unrestricted use, distribution, and reproduction in any medium, provided you give appropriate credit to the original author(s) and the source, provide a link to the Creative Commons license, and indicate if changes were made. 
$\lambda_{\mathrm{g}} / 4$ resonators is centered on the microstrip line, and a C-shaped slit is inserted into an elliptical patch. The proposed antenna satisfied the required bandwidth for UWB communication systems specified by the Federal Communications Commission, while maintaining dual-band rejection to prevent interference between bands.

The remainder of the paper is organized as follows: the "Background" section briefly introduces the proposal and design of the tapered slot antenna. The section, "Methodology and analyses of experimental data," deals with the characteristics of the antenna, which were analyzed through a simulation and measurement process. The "Result and discussion" section presents the comprehensive results for the proposed antenna. Finally, in the "Conclusion", we draw conclusions regarding the proposed antenna.

\section{Background}

\section{Antenna design}

For the structure of the proposed antenna, a $\lambda_{\mathrm{g}} / 4$ resonator and a C-shaped slit were inserted into an antenna. The antenna was designed with an elliptical patch structure, in order to reject both WiMAX and WLAN. It was fabricated using the Taconic TRF45 substrate, which is $1.62 \mathrm{~mm}$ in thickness and offers a relative permittivity of 4.5 and a loss tangent of 0.0035 . The structure of the antenna is compact, with a total size is $40 \times 35 \mathrm{~mm}^{2}$.

The design and analysis of the antenna were facilitated with HFSS, a commercial simulator tool available from Ansys. Its structure and design parameters are shown in Fig. 1 and Table 1 (Weng et al. 2010a, b).

Two bands coexist for unlicensed use in the UWB:WiMAX $(3.3-3.8 \mathrm{GHz})$ and WLAN $(5.15-5.85 \mathrm{GHz})$. The proposed antenna rejects both of these bands using a $\lambda_{\mathrm{g}} / 4$ resonator and a C-shaped slit (Sarkar et al. 2014; Wu et al. 2013).

The equivalent circuit for the proposed $\lambda_{\mathrm{g}} / 4$ resonator is shown in Fig. 2.

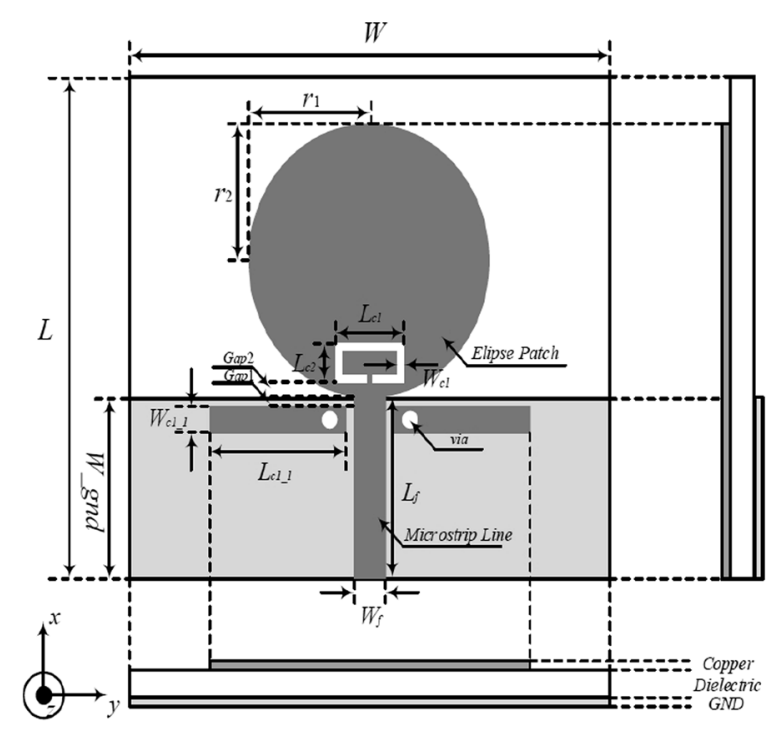

Fig. 1 Structure of the proposed UWB monopole antenna with dual-band rejection 
Table 1 Parameters of the proposed antenna $(\mathrm{mm})$

\begin{tabular}{llll}
\hline$L$ & 35 & $W$ & 40 \\
$L_{f}$ & 13.05 & $W_{f}$ & 2 \\
$r_{1}$ & 12 & $r_{2}$ & 10 \\
$L_{c 1}$ & 6.8 & $W_{c 1}$ & 3.2 \\
$L_{c 2}$ & 3.2 & $L_{c 1} 1$ & 11.6 \\
$W_{c 1 \_1}$ & 2 & $W_{-g n d}$ & 12 \\
Gap1 & 0.6 & Gap2 & 7.5
\end{tabular}

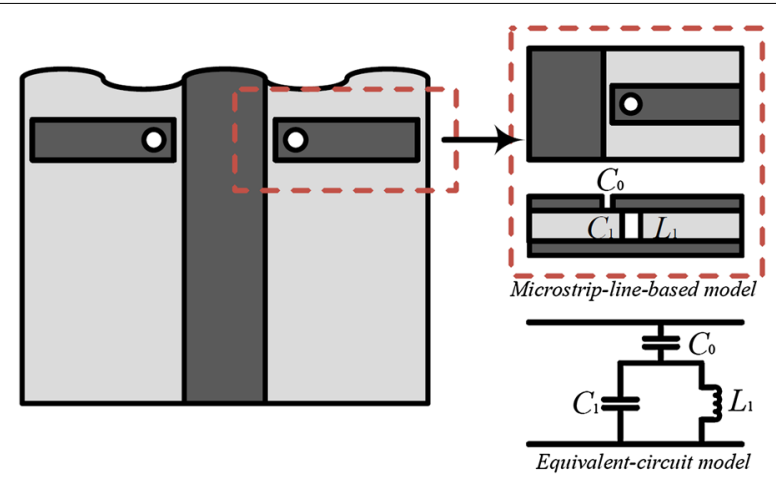

Fig. 2 The mechanism of the proposed $\lambda_{g} / 4$ resonator

The capacitance $C_{0}$ is the coupling generated between the microstrip line and the $\lambda_{\mathrm{g}} / 4$ resonator. The capacitance $C_{1}$ is derived from the voltage gradient between the $\lambda_{\mathrm{g}} / 4$ resonator and the ground plane, whereas inductance $\mathrm{L}_{1}$ is generated due to the current flowing through the pin. The rejection frequency is derived as follows (Trinh-Van and Dao-Ngoc 2011).

$$
f_{r}=\frac{1}{2 \pi \sqrt{L_{1}\left(C_{0}+C_{1}\right)}}
$$

In order to reject WiMAX, the following equation is used:

$$
L_{c 1-1}=\frac{\lambda_{g}}{4}
$$

where $L_{c 1 \_1}$ is the length of the resonator, and $\lambda_{g}$ is a guided wavelength.

$$
\lambda_{g}=\frac{\lambda_{0}}{\sqrt{\varepsilon_{e f f}}}=\frac{c}{f_{r} \sqrt{\varepsilon_{e f f}}}
$$

For the guided wavelength $\lambda_{\mathrm{g}}$, an effective dielectric constant $\varepsilon_{\text {eff }}$ must first be determined, along with a suitable length for the microstrip line. Here, $f$ denotes the frequency, and $c$ denotes the speed of light in a free space. An effective dielectric constant $\varepsilon_{\text {eff }}$ can be derived with the following equation:

$$
\varepsilon_{e f f}=\frac{\varepsilon_{r}+1}{2}+\frac{\varepsilon_{r}-1}{2}\left(1+\frac{12 h}{w}\right)^{-0.5}
$$


where $\varepsilon_{\mathrm{r}}$ is the relative permittivity of the substrate, and $h$ and $w$ denote the substrate thickness and the width of the microstrip, respectively. Next, $\mathrm{L}_{\mathrm{c} 1}$ and $\mathrm{L}_{\mathrm{c} 2}$ are calculated such that the C-shaped slits reject WLAN, and these are derived as follows (Xu et al. 2012; Hong and Lancaster 2004):

$$
L_{c 1, c 2}=\frac{\lambda_{g}}{2}
$$

Figure 3 depicts the size and look of the proposed UWB monopole antenna with dualband rejection.

\section{Methodology and analyses of proposed antenna}

The antenna is expressed by the reflection coefficient $\Gamma$, which is the amount of reflected signal due to the impedance mismatch between the source and the antenna.

The VSWR is calculated as follows (Chang 2000):

$$
\operatorname{VSWR}=\frac{1+|\Gamma|}{1-|\Gamma|}
$$

When $|\Gamma|=0$, optimal VSWR is obtained. This means that all power is transmitted to the antenna, and that there is no reflection. The impedance bandwidth of the antenna is defined at VSWR $\leq 2$, and it is the reflected value of approximately $11 \%$ input power (Chang 2000). Therefore, the proposed antenna has wide impedance bandwidth and powerful rejection-band characteristics.

We analyzed the characteristics of the proposed antenna in terms of its ability to perform dual-band rejection by simulating its current distribution, as shown in Fig. 4.

Figure 4 shows the field distribution pattern on the patch, along with its modification with a C-shaped slit and $\lambda_{\mathrm{g}} / 4$ resonators. The proposed antenna had a concentrated current at the $\lambda_{\mathrm{g}} / 4$ resonator over the $3.5 \mathrm{GHz}$ band (WiMAX), and a further concentration at the C-shape slits over the $5.5 \mathrm{GHz}$ band (WLAN). The dual-band rejection and impedance bandwidth for the proposed antenna were analyzed for each structure using the voltage standing-wave ratio (VSWR). All three structures and their corresponding VSWR are shown in Figs. 5 and 6, respectively.

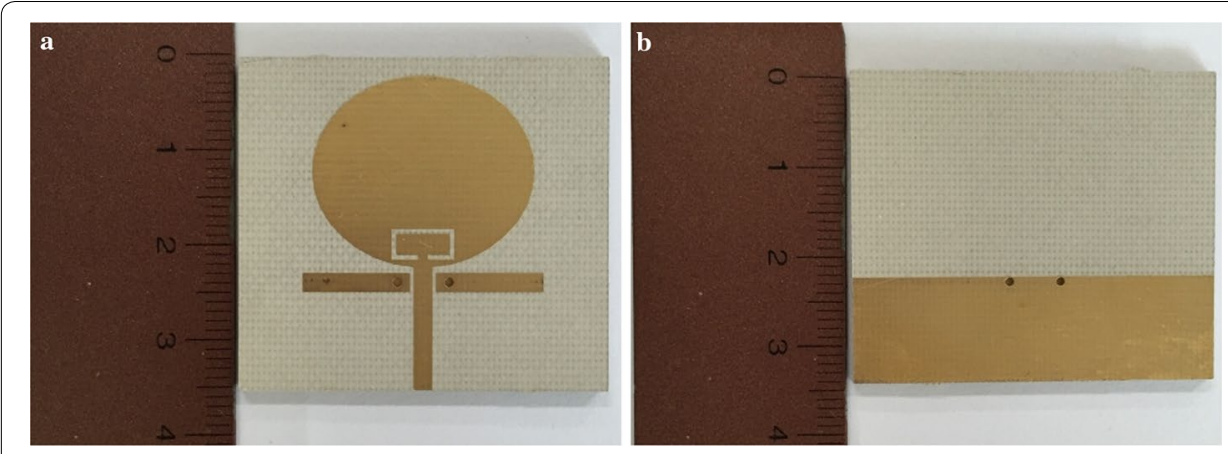

Fig. 3 Size and look of the proposed antenna. a Front side, b Rear side 

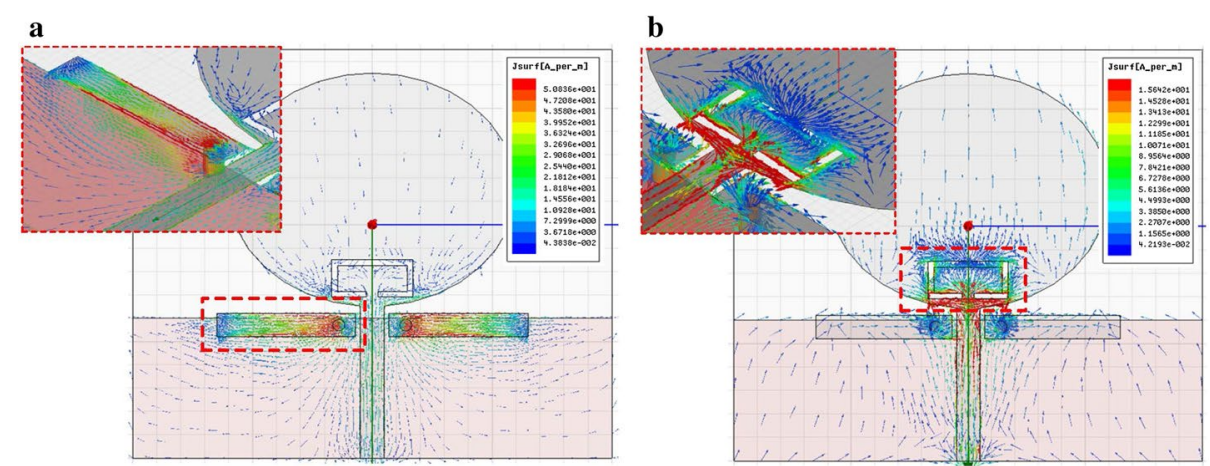

Fig. 4 Simulated analysis of the current distribution for the proposed antenna. a $3.5 \mathrm{GHz}$ band (WiMAX), b $5.5 \mathrm{GHz}$ band (WLAN)
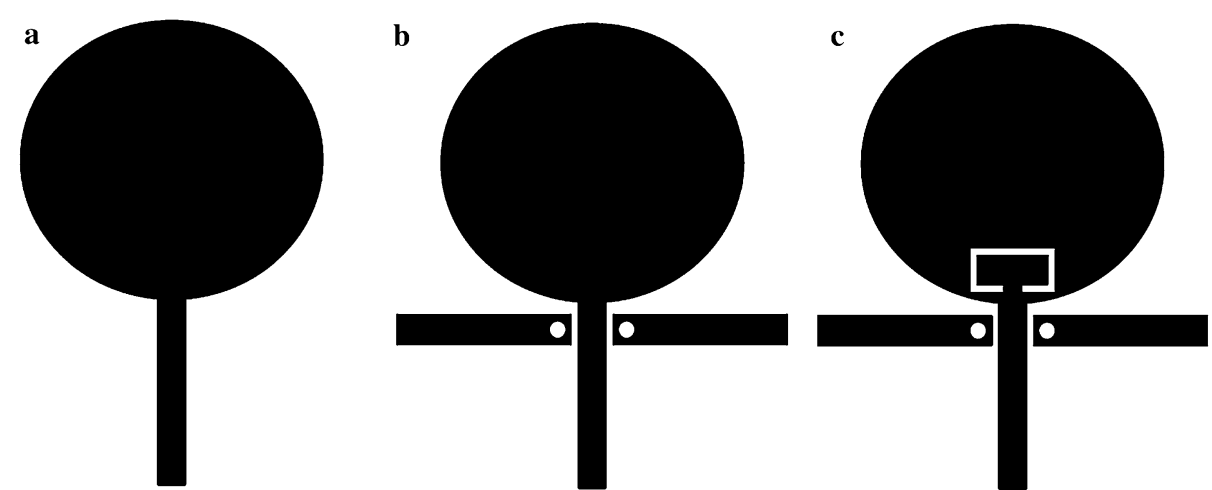

Fig. 5 Three structuresfor the proposed antenna. a Structure-1, b Structure-2, c Structure-3

As shown in Fig. 6, Structure-1 converged with a VSWR $\leq 2$ over the $3.27-10.48 \mathrm{GHz}$ band, thereby satisfying the impedance bandwidth for standard UWB communication systems. Structure-2 successfully rejected the $3.27-3.87 \mathrm{GHz}$ band, and its impedance

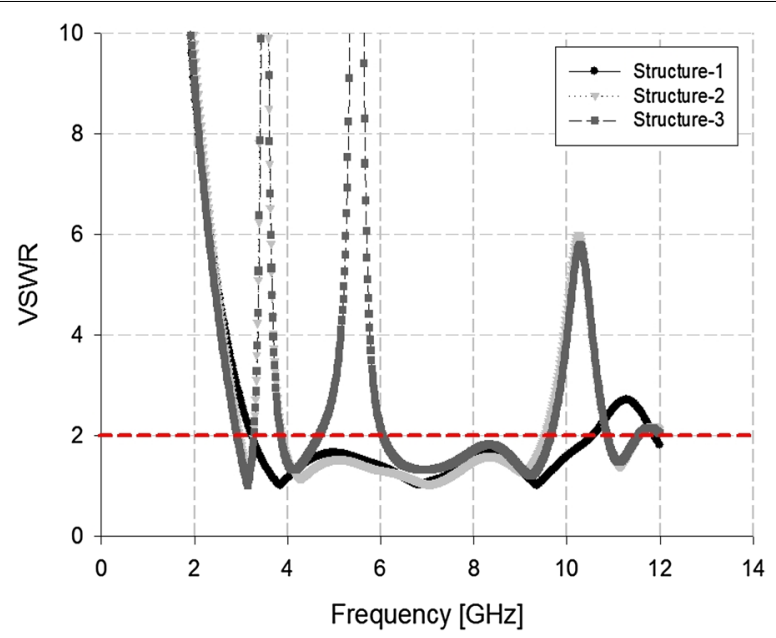

Fig. 6 VSWR analysis using a simulationof the proposed antenna 
bandwidth converged with a VSWR $\leq 2$ at the $2.99-9.50 \mathrm{GHz}$ band. Structure-3 successfully rejected both the $3.28-3.85 \mathrm{GHz}$ band and the $4.7-6.03 \mathrm{GHz}$ band, and its impedance bandwidth converged with a VSWR $\leq 2$ at the $2.94-9.63 \mathrm{GHz}$ band. Therefore, we demonstrated that dual-band rejection is feasible, and we verified that the proposed structure offers suitably high bandwidth for UWB communications.

Either the WLAN band or the WiMAX band can be rejected with physical changes to the C-shape slits or the $\lambda_{\mathrm{g}} / 4$ resonator of the proposed antenna, respectively. Thus, the WiMAX band can be rejected through physical changes to the $\lambda_{\mathrm{g}} / 4$ resonator, as shown in Fig. 7.

Figure 7 shows that, as the length of the $\lambda_{\mathrm{g}} / 4$ resonator increased from 9.6 to $13.6 \mathrm{~mm}$, the rejected band shifted to a higher frequency. At $11.6 \mathrm{~mm}$, the WiMAX band was exclusively rejected.

The WLAN band can likewise be rejected by making physical changes to the C-shaped slits, as shown in Fig. 8.

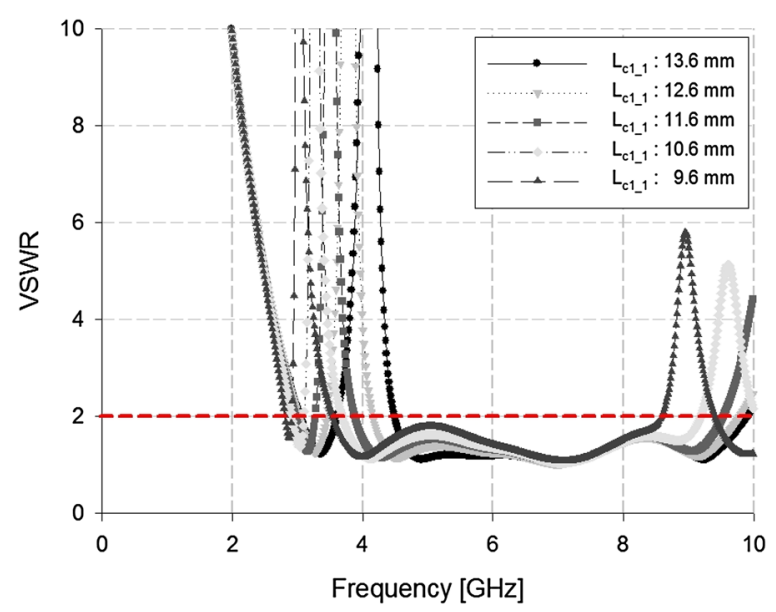

Fig. 7 VSWR analysis of the $\lambda_{\mathrm{g}} / 4$ resonator

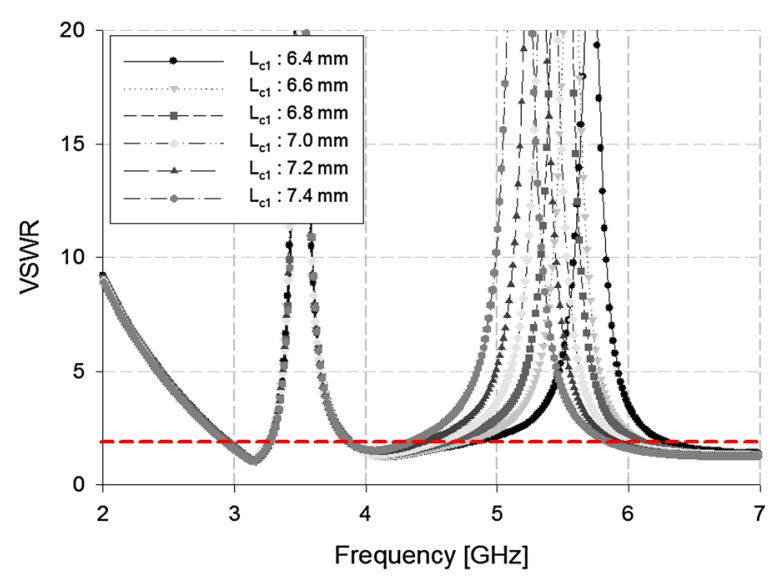

Fig. 8 VSWR analysis of the C-shaped slit 
Figure 8 shows that, as the length of the C-shaped slit increased from 6.4 to $7.4 \mathrm{~mm}$, the rejected band shifted to a lower frequency. At $6.8 \mathrm{~mm}$, the WLAN band was exclusively rejected.

In order to confirm the reliability of the band rejections with the proposed antenna, we analyzed the gaps between the antenna and the $\lambda_{\mathrm{g}} / 4$ resonator and between the antenna and the C-shaped slit. Our analysis showed that a higher VSWR resulted in superior band rejections, owing to an impedance mismatch. We performed this analysis by varying the gap between the $\lambda_{\mathrm{g}} / 4$ resonator and the antenna to $1.2 \mathrm{~mm}$, the results for which (i.e., exclusively rejecting WiMAX) are shown in Fig. 9.

As shown in Fig. 9, as the gap narrowed between the antenna and the $\lambda_{\mathrm{g}} / 4$ resonator, the VSWR increased and antenna gain reduced to below $-10 \mathrm{dBi}$.

We then modified the gap between the $\mathrm{C}$-shaped slit and the antenna to $1 \mathrm{~mm}$, and the results of this modification (i.e., exclusively rejecting WLAN) are shown in Fig. 10.

As shown in Fig. 10, as the gap narrowed between the antenna and the C-shaped slit, the VSWR increased and antenna gain reduced to below $-8 \mathrm{dBi}$.

The overall characteristics of the proposed antenna in terms of its ability to reject WLAN and WiMAX are provided in Table 2.
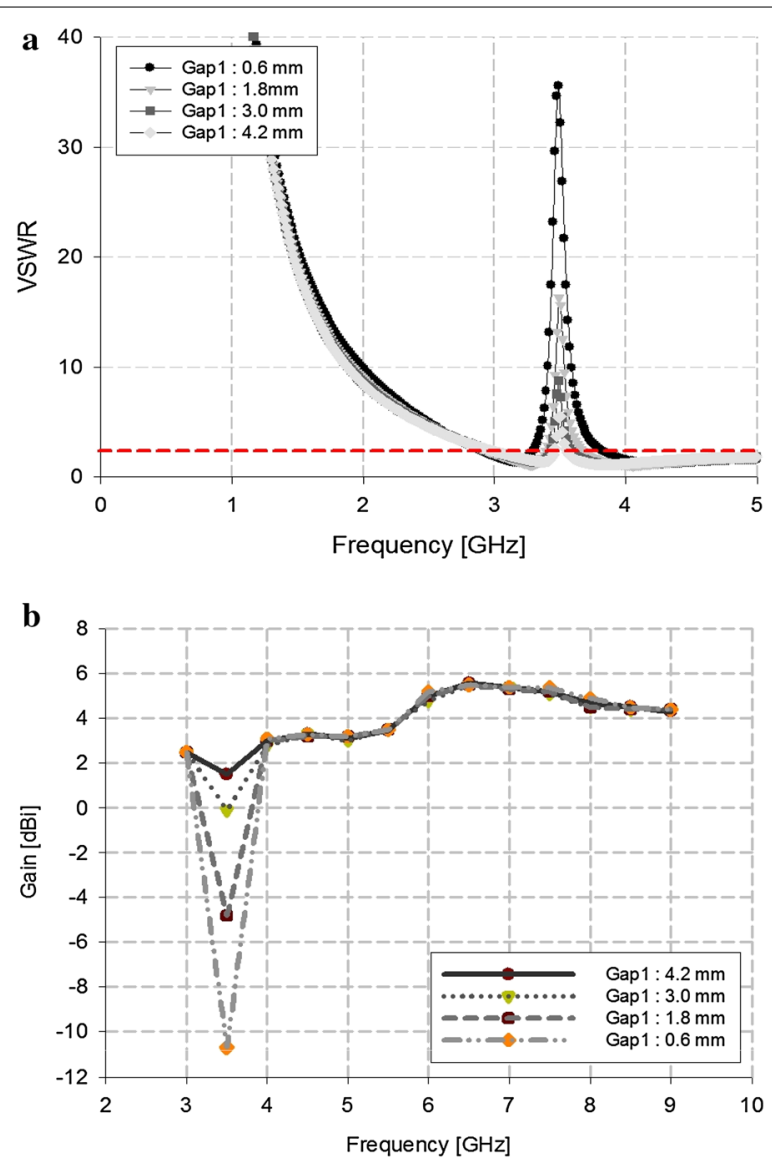

Fig. 9 Analysis of the WiMAX-band rejection. a VSWR, b Antenna gain 


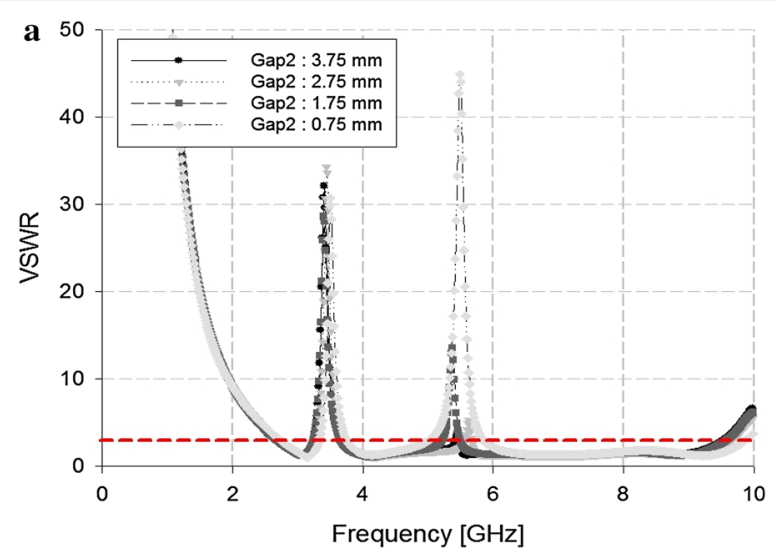

b

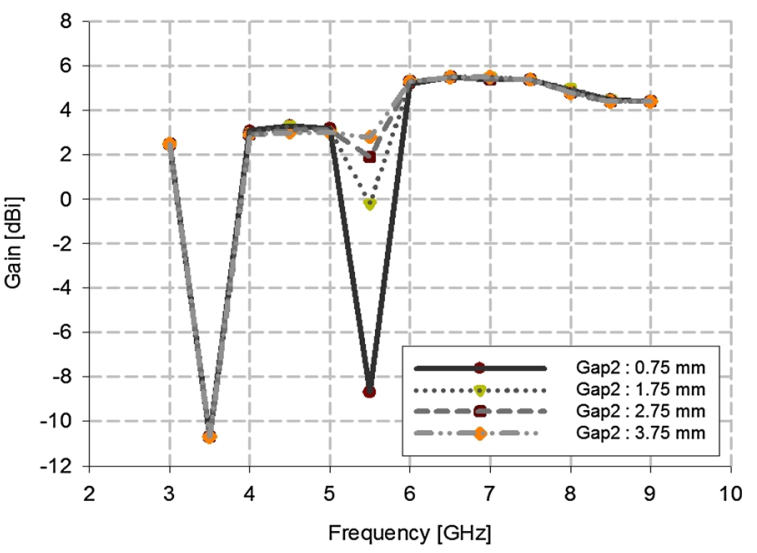

Fig. 10 Analysis of the WLAN-band rejection. a VSWR, $\mathbf{b}$ antenna gain

Table 2 Analysis of the antenna's band rejection

\begin{tabular}{lcr}
\hline & VSWR & Gain (dB) \\
\hline WiMAX & & \\
Gap 1: $0.6 \mathrm{~mm}$ & 37.5 & -10.7 \\
Gap 1: $1.8 \mathrm{~mm}$ & 16.2 & -4.8 \\
Gap 1: $3.0 \mathrm{~mm}$ & 8.6 & -0.1 \\
Gap 1: $4.2 \mathrm{~mm}$ & 5.5 & 1.5 \\
WLAN & & \\
Gap 2: $0.75 \mathrm{~mm}$ & 44.9 & -8.7 \\
Gap 2: $1.75 \mathrm{~mm}$ & 13.5 & -0.2 \\
Gap 2: $2.75 \mathrm{~mm}$ & 5.3 & 1.9 \\
Gap 2: $3.75 \mathrm{~mm}$ & 4.0 & 2.8 \\
\hline
\end{tabular}

Table 2 shows that, for WiMAX, the antenna gain was $-10.7 \mathrm{~dB}$ when Gap 1 was $0.6 \mathrm{~mm}$. For WLAN, the antenna gain was $-8.7 \mathrm{~dB}$ when Gap 2 was $0.75 \mathrm{~mm}$. These results confirm the feasibility of the proposed antenna with dual-band rejection. 


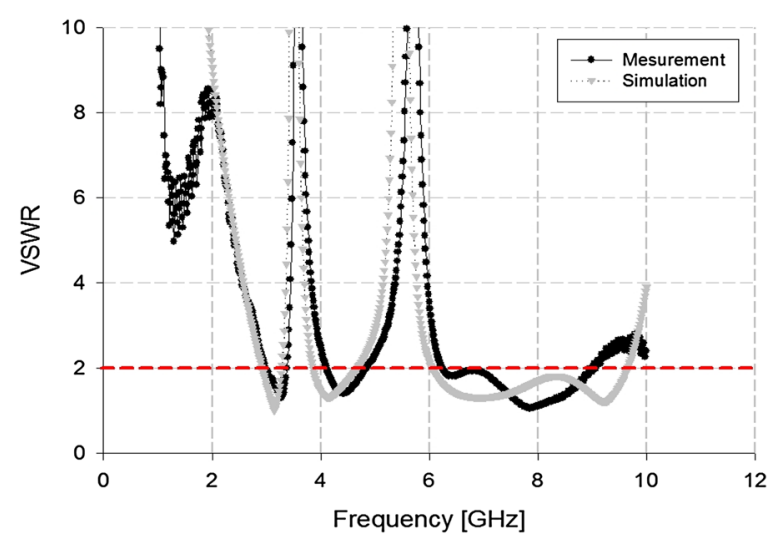

Fig. 11 VSWR analysis of the proposed antenna

The UWB monopole patch antenna was also evaluated using a simulation, and these results are shown in Fig. 11.

As shown in Fig. 11, the impedance bandwidth of the proposed antenna satisfied dualband rejection at two bands: 3.3-3.85 and 4.8-6.1 GHz. Its impedance bandwidth converged with a VSWR $\leq 2$ over the $2.9-9.3 \mathrm{GHz}$ band. Therefore, the simulation results are consistent with the measurement results.

To further evaluate the proposed antenna, we used a simulation to analyze the radiation pattern along the E-plane (XZ-plane) and H-plane (YZ-plane) over two bands, 4 and $7 \mathrm{GHz}$, the results for which are shown in Fig. 12.

As shown in Fig. 12, the analysis of the radiation pattern of the proposed antenna demonstrated its omnidirectional characteristics at the 4 and $7 \mathrm{GHz}$ bands.

The antenna gain of the proposed antenna over all bands was also analyzed, and the results from this analysis are shown in Fig. 13.

As shown in Fig. 13, the analysis of the proposed antenna's gain revealed that the simulation and measurement results were similar. However, the simulation analysis results and measurement results at $5.5 \mathrm{GHz}$ were different by approximately $6 \mathrm{dBi}$. This was because of the loss in the physical size of the $\mathrm{C}$-shaped slot during the production process. However, the band-rejection proceeded downward below $0 \mathrm{dBi}$, which is a suitable value.

\section{Results and discussion}

The overall analysis results in Table 3 show that the proposed antenna offers the appropriate bandwidth for UWB communication systems, coupled with dual-band rejection to avoid interference between communication systems. These results also show that the radiation pattern of the antenna is omnidirectional.

A mismatch was observed between the simulation results and the measured results for the proposed antenna. This occurred in two forms: the first pertained to errors during the manufacturing process, and the second to loss between the antenna and the connector. However, this mismatch is not a major problem with the proposed performance. On this basis, the impedance bandwidth was achieved with a VSWR $\leq 2$, and the rejected band proceeded downward below $0 \mathrm{dBi}$. 

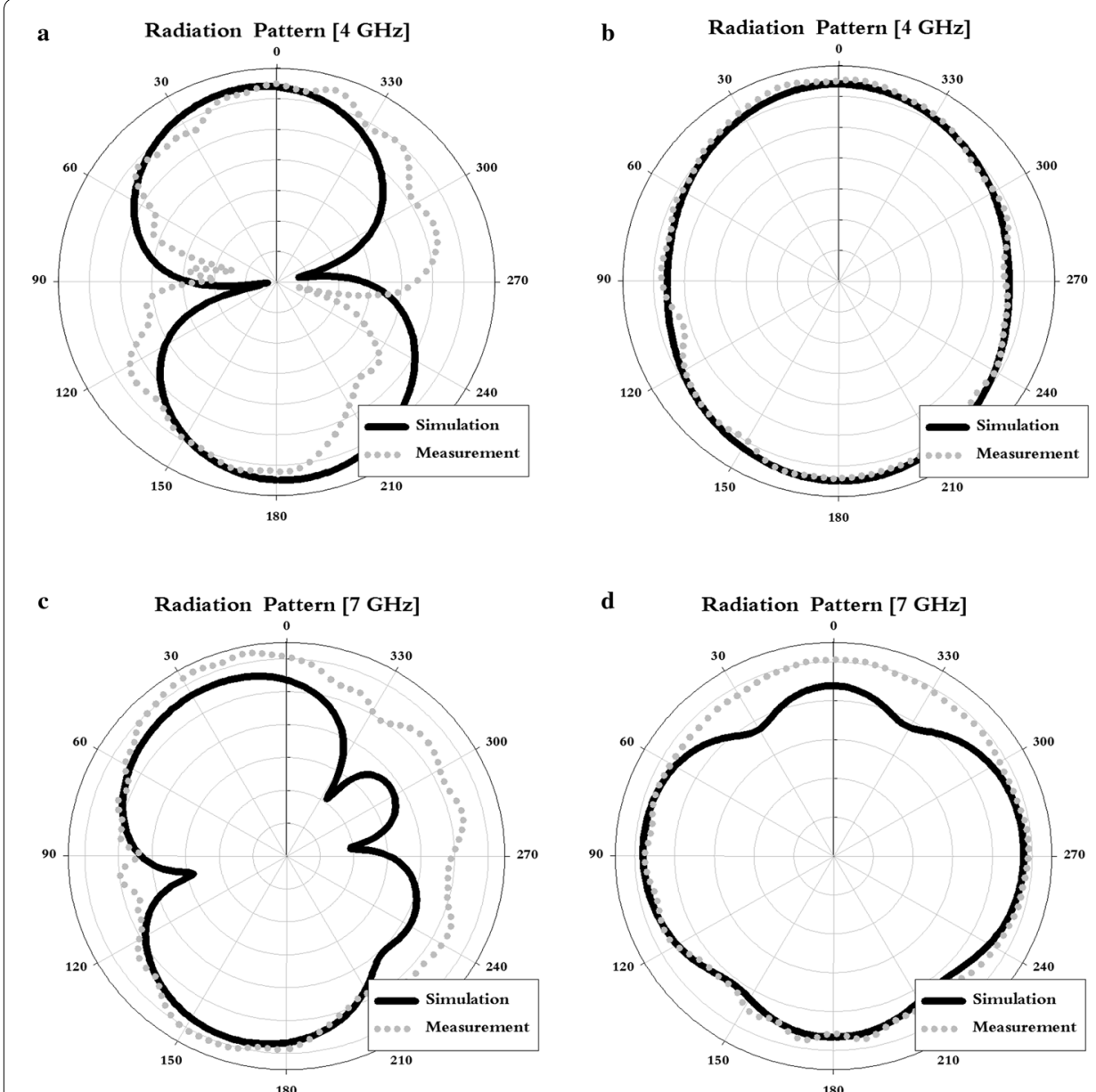

Fig. 12 Analysis on the radiation pattern of the proposed antenna. a E-plane of $4 \mathrm{GHz}$ (XZ-plane), b H-plane of $4 \mathrm{GHz}$ (YZ-plane), c E-plane of $7 \mathrm{GHz}$ (XZ-plane), $\mathbf{d} \mathrm{H}$-plane of $7 \mathrm{GHz}$ (YZ-plane)

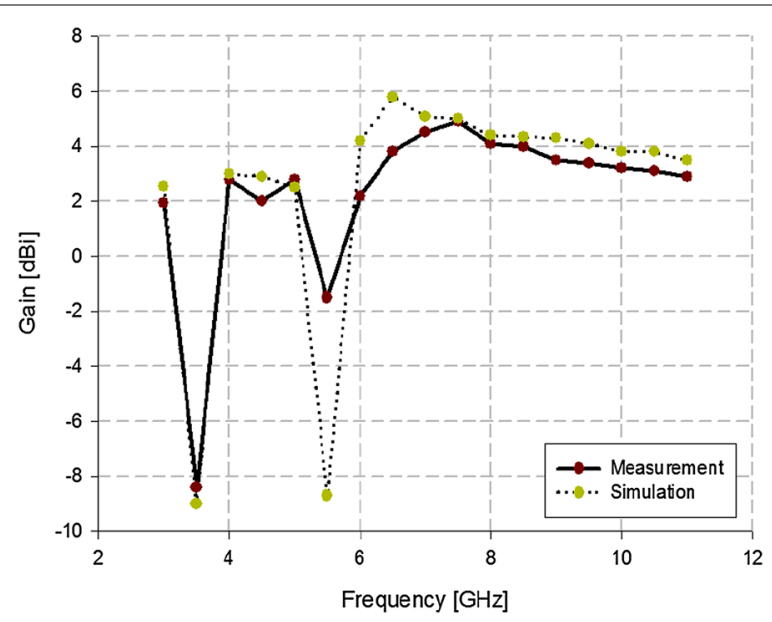

Fig. 13 Analysis on the antenna gain of the proposed antenna 
Table 3 Overall analysis of the proposed antenna

\begin{tabular}{lll}
\hline Simulation results & & \\
Impedance bandwidth & $2.94-9.63 \mathrm{GHz}$ & \\
Dual-band notched bandwidth & $3.28-3.85 \mathrm{GHz}$ & \\
Antenna gain [dBi] & $4.7-6.03 \mathrm{GHz}$ & $2.53 \mathrm{~dB}$ \\
& $3 \mathrm{GHz}$ & $-9.0 \mathrm{~dB}$ \\
& $3.5 \mathrm{GHz}$ & $2.50 \mathrm{~dB}$ \\
& $5 \mathrm{GHz}$ & $-8.7 \mathrm{~dB}$ \\
Measurement results & $5.5 \mathrm{GHz}$ & $5.09 \mathrm{~dB}$ \\
Impedance bandwidth & $7 \mathrm{GHz}$ & $4.31 \mathrm{~dB}$ \\
Dual-band notched bandwidth & $9 \mathrm{GHz}$ & \\
Antenna gain & & \\
& $2.9-9.3 \mathrm{GHz}$ & \\
& $3.3-3.85 \mathrm{GHz}$ & $1.95 \mathrm{~dB}$ \\
& $4.8-6.1 \mathrm{GHz}$ & $-8.4 \mathrm{~dB}$ \\
& $3 \mathrm{GHz}$ & $2.79 \mathrm{~dB}$ \\
& $3.5 \mathrm{GHz}$ & $-1.5 \mathrm{~dB}$ \\
& $5 \mathrm{GHz}$ & $4.51 \mathrm{~dB}$ \\
& $5.5 \mathrm{GHz}$ & $3.50 \mathrm{~dB}$ \\
\hline
\end{tabular}

Table 4 Comparison of the proposed antenna and different antennas

\begin{tabular}{lcc}
\hline Antenna & Rejected band (GHz) & Dimensions ( $\mathbf{m m}^{\mathbf{2}}$ ) \\
\hline Trinh-Van and Dao-Ngoc (2011) & $3.375-3.875$ & $42.5 \times 34$ \\
& $5.325-6.150$ & \\
Dong et al. (2014) & $4.96-5.42$ & $38 \times 44$ \\
Satyanarayana and Mulgi (2015) & $5.71-5.91$ & \\
Proposed antenna & $3.2-4.2$ & $38 \times 50$ \\
& $3.2-3.85$ & $40 \times 35$ \\
& $4.7-6.03$ & \\
\hline
\end{tabular}

The proposed antenna is compared to other antennas with rejected-band characteristics in Table 4. The advantage of the proposed antenna lies in its compact design and the fact that it has a dual-band rejection characteristic.

\section{Conclusion}

In this paper, we proposed a UWB monopole patch antenna with dual-band rejection. The impedance bandwidth of the proposed antenna satisfied VSWR $\leq 2$ at the 2.9-9.3 GHz band and dual-band rejection from an impedance mismatch at the 3.3-3.85 and 4.8-6.1 GHz bands. Furthermore, we demonstrated that the antenna's radiation pattern is omnidirectional, and that the antenna gain proceeded downward to below $0 \mathrm{dBi}$ for dual-band rejection. Furthermore, the proposed antenna offers the advantage of dualband rejection and a compact design, compared with different antennas.

The design of the proposed antenna was optimized through HFSS, a commercial electromagnetic simulator provided by Ansys. The antenna was designed using the Taconic TRF-45 substrate, which is $1.62 \mathrm{~mm}$ thick with a relative permittivity of 4.5 and a loss tangent of 0.0035 . 


\section{Authors' contributions}

SWK involves in design and interpretation of statistical analysis of collected data along with drafting of the manuscript. DYC have been involved for supervision, guidance and critically reviewing manuscript for important intellectual content. Both authors read and approved the final manuscript.

\section{Competing interests}

The authors declare that there is no competing interests.

Received: 19 April 2016 Accepted: 16 June 2016

Published online: 24 June 2016

\section{References}

Chang K (2000) RF and microwave wireless system. Wiley, New York, pp 74-75

Dadgarpour A, Dadashzadeh G, Naser-Moghadasi M, Jolani F (2009) Design and optimization of compact balanced antipodal staircase bow-tie antenna. IEEE Antenna Wirel Propag Lett 8:1135-1138

Dong D, Chen S, Liao Z, Liu G (2014) A CPW-Fed dual-band-notched antenna with sharp skirt selectivity for UWB applications. Int J Antenna Propag 2014:629387. doi:10.1155/2014/629387

Dullaert W, Rogier H (2010) Novel compact model for the radiation pattern of UWB Antennas using vector spherical and slepian decomposition. IEEE Trans Antenna Propag 58(2):287-299

Hong JSG, Lancaster MJ (2004) Microstrip filters for RF/microwave applications. Wiley, London

Hood AZ, Karacolak T, Topsakal E (2008) A small antipodal vivaldi antenna for ultrawide-band applications. IEEE Antenna Wirel Propag Lett 7:656-660

Jang JW, Hwang HY (2008) Design of a miniaturized quarter-circular-slot UWB antenna. Microwave J

Kim DO, Kim CY (2010) CPW-fed ultra-wideband antenna with triple-band notch function. Electron Lett 46(18):1246-1248

Kim TG, Min KS (2009) Design for trapezoidal planar UWB antenna using symmetry meander feedline. J Korea Electromagn Eng Soc 20(2):739-745

Kiminami K, Hirata A (2004) Double-sided printed bowtie antenna for UWB communications. IEEE Antenna Wirel Propag Lett 3:152-153

Oraizi H, Hedayati S (2011) Miniaturized UWB monopole microstrip antenna design by the combination of Giusepe Peano and Sierpinski Carpet fractals. IEEE Antenna Wirel Propag Lett 10:67-70

Sarkar D, Srivastava KV, Saurav K (2014) A compact microstrip-fed triple band-notched UWB monopole antenna. IEEE Antenna Wirel Propag Lett 13:396-399

Satyanarayana B, Mulgi S (2015) Design of planar band-notched monopole antenna for 2.4 GHz WLAN and UWB applications. Microw Opt Technol Lett 57(11):2496-2501

Trinh-Van S, Dao-Ngoc C (2011) Dual band-notched UWB antenna based on electromagnetic band gap structures. REV J Electr Commun 1(2):130-136

Weng YF, Cheung SW, Yuk TI (2010a) Band-notched characteristic using meandered ground stubs for compact UWB antennas. Proceedings of 2010 IEEE international conference on ultra-wideband

Weng YF, Cheung SW, Yuk TI (2010b) Triple band-notched UWB antenna using meandered ground stubs 2010 Loughborough Antennas and propagation conference

Wu ZH, Wei F, Shi XW, Li WT (2013) A compact quad band-notched UWB monopole antenna loaded one lateral L-shaped slot. Prog Electromagn Res 139:303-315

Xu J, Shen DY, Wang GT, Zhang XH, Zhang XP, Wu K (2012) A small UWB antenna with dual band-notched characteristics. Int J Antenna Propag 2012:656858. doi:10.1155/2012/656858

\section{Submit your manuscript to a SpringerOpen ${ }^{\circ}$ journal and benefit from:}

- Convenient online submission

- Rigorous peer review

- Immediate publication on acceptance

- Open access: articles freely available online

- High visibility within the field

- Retaining the copyright to your article

Submit your next manuscript at $>$ springeropen.com 